\title{
DYNAMIC SYNTHESIS OF THE ROTARY CAM AND TRANSLATED TAPPET WITH ROLL
}

\author{
Florian Ion Petrescu \\ Senior Lecturer Ph.D. Eng. Florian Ion PETRESCU, \\ Bucharest Polytechnic University, petrescuflorian@yahoo.com \\ Relly Victoria Petrescu \\ Senior Lecturer Ph.D. Eng. Relly Victoria PETRESCU, \\ Bucharest Polytechnic University, petrescuvictoria@yahoo.com
}

\begin{abstract}
This paper presents an original method to determine the dynamic parameters at the camshaft (the distribution mechanisms). The authors introduce a new pressure angle, alpha, and a new method to determine the two pressure angles, alpha and delta, at the rotary cam and tappet with translational motion with roll, with a great precision. We determine initially the mass moment of inertia (mechanical) of the mechanism, reduced to the element of rotation, ie at cam (basically using kinetic energy conservation, the system 1). The rotary cam with translated follower with roll (Figure 1), is synthesized dynamic. We considered the law of motion of the tappet classic version already used the cosine law (both ascending and descending). The angular velocity is a function of the cam position $(\varphi)$ but also its rotation speed (2). Where $\omega m$ is the nominal angular velocity of cam and express at the distribution mechanisms based on the motor shaft speed (3). We start the simulation with a classical law of motion, namely the cosine law. To climb cosine law system is expressed by relations (4). With the relation (5) is expressed the first derivative of the reduced mechanical moment of inertia. It is necessary to determine the angular acceleration (6). Relations (2) and (6) a general nature and is basically two original equations of motion crucial for mechanical mechanisms. For a rotary cam and translated tappet with roll mechanism (without valve), dynamic movement tappet is expressed by equation (7). Where $\mathrm{x}$ is the dynamic movement of the pusher, while $\mathrm{s}$ is its normal, kinematics movement. $\mathrm{K}$ is the spring constant of the system, and $\mathrm{k}$ is the spring constant of the tappet spring. It note, with $\mathrm{x} 0$ the tappet spring preload, with $\mathrm{mT}$ the mass of the tappet, with $\omega$ the angular rotation speed of the cam (or camshaft), where s' is the first derivative in function of $\varphi$ of the tappet movement, s. Differentiating twice successively, the expression (7) in the angle $\varphi$, we obtain a reduced tappet speed (equation 8), and reduced tappet acceleration (9). Further the acceleration of the tappet can be determined directly real (dynamic) using the relation (10). For a good work one proposes to make a new geometro-kinematics synthesis of the cam profile, using some new relationships (16).
\end{abstract}

Keywords: cam, cams, cam mechanisms, distribution mechanisms, camshaft, tappet. 


\section{INTRODUCTION}

Development and diversification of machines and mechanisms with applications in all areas of scientific research requires new systematization and improvement of existing mechanical systems by creating new mechanisms adapted to the modern requirements, which involve more complex topological structures.

Modern industry, the practice of engineering design and construction are increasingly based on scientific research and practical results.

Each achievement is backed Industrial theoretical and experimental research aided by resolving more complex problems with advanced computer programs, using specialized software more.

Processes robotization increasingly determine and influence the emergence of new industries, applications in specific environmental conditions, approach new types of technological operations, handling of objects in outer space, leading teleoperator in disciplines such as medicine, robots that covers a whole larger service benefits our society, modern and computerized.

In this context, this paper seeks to contribute to the scientific and technical applications in dynamic analysis and synthesis of cam mechanisms.

In 1971 K. Hain proposes an optimization method to cam mechanism to achieve the optimum output transmission angle (maximum) and minimum acceleration [4].

In 1979 F. Giordano investigates the influence of measurement errors in kinematic analysis of cam [3].

In 1985 P. Antonescu presents an analytical method for the synthesis mechanism flat tappet cam and tappet rocker mechanism [2].

In 1988 J. Angeles and C. Lopez-Cajun presents optimal synthesis mechanism oscillating flat tappet cam and [1].

In 2001 Taraza Dinu synthesized analyzes the influence of the cam profile, the variation of the angular velocity distribution tree, and the parameters of power load consumption and emissions of internal combustion engine [9].

In 2005 F.I. Petrescu and R.V. Petrescu present a synthesis method of rotating tappet cam profile translational or rotary flat or roll to obtain high yields output [5-8].
In this paper one presents an original method to determine the dynamic parameters at the camshaft (the distribution mechanisms). It makes the synthesis, of the rotary cam and tappet with translational motion with roll, with a great preci-

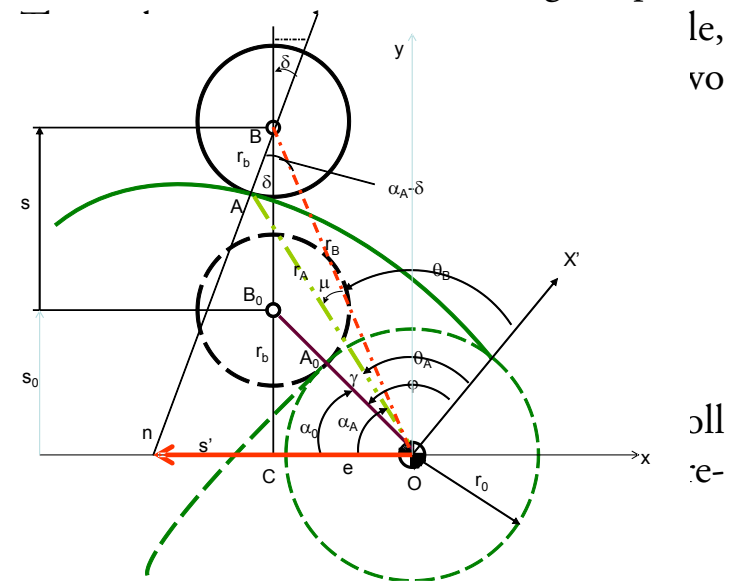

Fig. 1 The rotary cam with translated follower with roll

First, one determines the mass moment of inertia (mechanical) of the mechanism, reduced to the element of rotation, ie cam (basically using kinetic energy conservation, system 1).

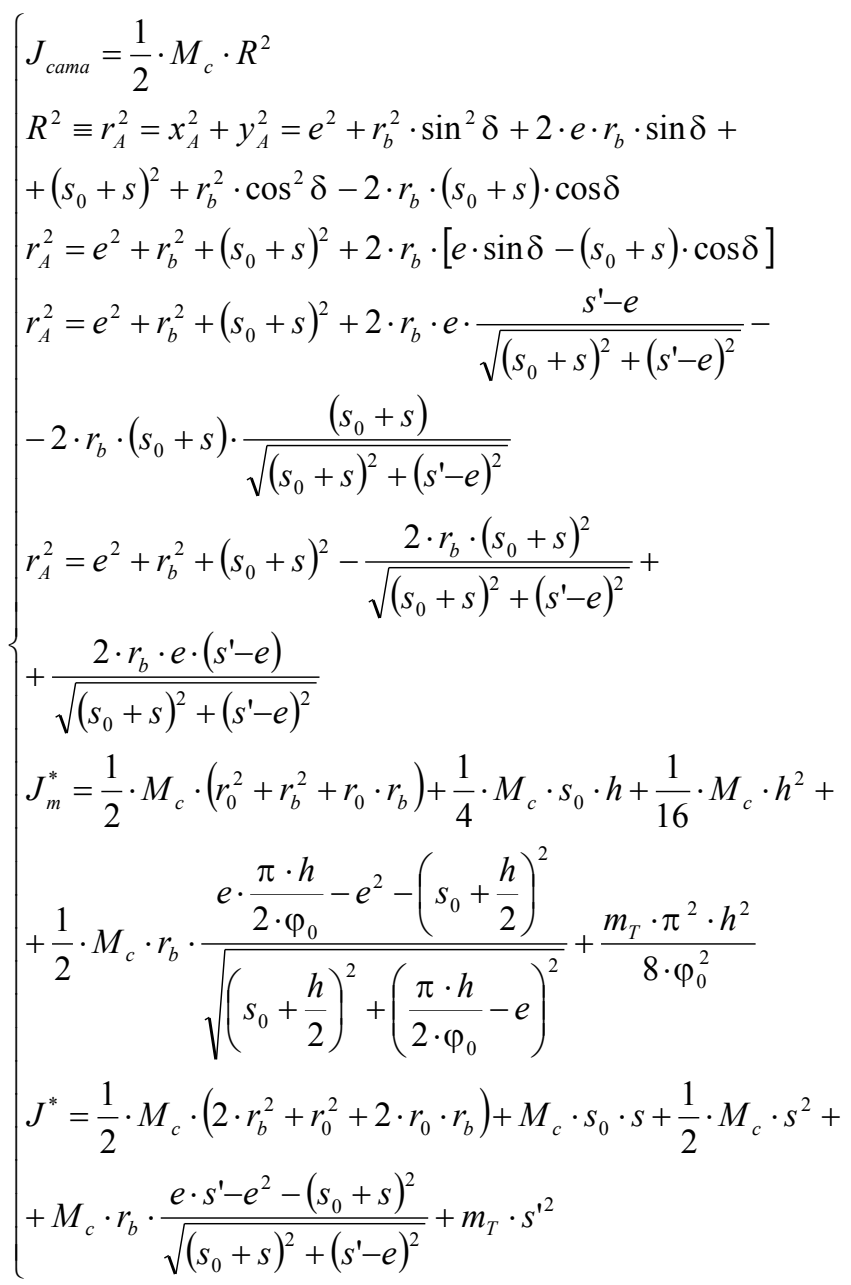


We considered the law of motion of the tappet classic version already used the cosine law (both ascending and descending).

The angular velocity is a function of the cam position $(\varphi)$ but also its rotation speed (2). Where $\omega_{\mathrm{m}}$ is the nominal angular velocity of cam and express at the distribution mechanisms based on the motor shaft speed (3).

$$
\begin{gathered}
\omega^{2}=\frac{J_{m}^{*}}{J^{*}} \cdot \omega_{m}^{2} \\
\omega_{m}=2 \cdot \pi \cdot v_{c}=2 \cdot \pi \cdot \frac{n_{c}}{60}= \\
=\frac{2 \cdot \pi}{60} \cdot \frac{n_{\text {motor }}}{2}=\frac{\pi \cdot n}{60}
\end{gathered}
$$

We start the simulation with a classical law of motion, namely the cosine law. To climb cosine law system is expressed by relations (4).

(4)

$$
\left\{\begin{array}{l}
s=\frac{h}{2}-\frac{h}{2} \cdot \cos \left(\pi \cdot \frac{\varphi}{\varphi_{u}}\right) \\
s^{\prime} \equiv v_{r}=\frac{\pi \cdot h}{2 \cdot \varphi_{u}} \cdot \sin \left(\pi \cdot \frac{\varphi}{\varphi_{u}}\right) \\
s^{\prime \prime} \equiv a_{r}=\frac{\pi^{2} \cdot h}{2 \cdot \varphi_{u}^{2}} \cdot \cos \left(\pi \cdot \frac{\varphi}{\varphi_{u}}\right) \\
s^{\prime \prime \prime} \equiv \alpha_{r}=-\frac{\pi^{3} \cdot h}{2 \cdot \varphi_{u}^{3}} \cdot \sin \left(\pi \cdot \frac{\varphi}{\varphi_{u}}\right)
\end{array}\right.
$$

Where $\varphi$ takes values from 0 to $\varphi_{\mathrm{u}}$. $\mathrm{J}_{\max }$ occurs for $\varphi=\varphi_{\mathrm{u}} / 2$.

With the relation (5) is expressed the first derivative of the reduced mechanical moment of inertia. It is necessary to determine the angular acceleration (6).

$$
\begin{aligned}
& J^{* \prime}=M_{c} \cdot s_{0} \cdot s^{\prime}+M_{c} \cdot s \cdot s^{\prime}+2 \cdot m_{T} \cdot s^{\prime} \cdot s^{\prime \prime}+M_{c} \cdot r_{b} \cdot \\
& \frac{\left[e \cdot s^{\prime \prime}-2 \cdot\left(s_{0}+s\right) \cdot s^{\prime}\right] \cdot\left[\left(s_{0}+s\right)^{2}+\left(s^{\prime}-e\right)^{2}\right]}{\left[\left(s_{0}+s\right)^{2}+\left(s^{\prime}-e\right)^{2}\right]^{3 / 2}}- \\
& -M_{c} \cdot r_{b} \cdot \\
& \frac{\left[e \cdot s^{\prime}-e^{2}-\left(s_{0}+s\right)^{2}\right] \cdot\left[\left(s_{0}+s\right) \cdot s^{\prime}+\left(s^{\prime}-e\right) \cdot s^{\prime \prime}\right]}{\left[\left(s_{0}+s\right)^{2}+\left(s^{\prime}-e\right)^{2}\right]^{3 / 2}}
\end{aligned}
$$

Differentiating the formula (2), against time, is obtained the angular acceleration expression (6).

$$
\varepsilon=-\frac{\omega^{2}}{2} \cdot \frac{J^{* \prime}}{J^{*}}
$$

Relations (2) and (6) a general nature and is basically two original equations of motion crucial for mechanical mechanisms.

For a rotary cam and translated tappet with roll mechanism (without valve), dynamic movement tappet is expressed by equation (7), who was presented and derived in Chapter 2 (equation 48 ), and now by canceling valve mass, will customize and reaching form below (7).

$$
\begin{aligned}
& x=s- \\
& -\frac{(K+k) \cdot m_{T} \cdot \omega^{2} \cdot s^{\prime 2}+\left(k^{2}+2 k \cdot K\right) \cdot s^{2}+2 k \cdot x_{0} \cdot(K+k) \cdot s}{2 \cdot(K+k)^{2} \cdot\left(s+\frac{k \cdot x_{0}}{K+k}\right)}
\end{aligned}
$$

Where $\mathrm{x}$ is the dynamic movement of the pusher, while $s$ is its normal, kinematics movement. $\mathrm{K}$ is the spring constant of the system, and $\mathrm{k}$ is the spring constant of the tappet spring.

It note, with $\mathrm{x}_{0}$ the tappet spring preload, with $\mathrm{m}_{\mathrm{T}}$ the mass of the tappet, with $\omega$ the angular rotation speed of the cam (or camshaft), where s' is the first derivative in function of $\square$ of the tappet movement, s. Differentiating twice successively, the expression (7) in the angle $\square$, we obtain a reduced tappet speed (equation 8), and reduced tappet acceleration (9). 


$$
\left\{\begin{array}{l}
N=(K+k) \cdot m_{T} \cdot \omega^{2} \cdot s^{\prime 2}+ \\
+\left(k^{2}+2 k \cdot K\right) \cdot s^{2}+2 k \cdot x_{0} \cdot(K+k) \cdot s \\
M=\left[(K+k) m_{T} \omega^{2} \cdot 2 s^{\prime} s^{\prime \prime}+\left(k^{2}+2 k K\right) \cdot 2 s s^{\prime}+\right. \\
\left.+2 k x_{0}(K+k) \cdot s^{\prime}\right] \cdot\left(s+\frac{k x_{0}}{K+k}\right)-N \cdot s^{\prime} \\
x^{\prime}=s^{\prime}-\frac{M}{2 \cdot(K+k)^{2} \cdot\left(s+\frac{k x_{0}}{K+k}\right)^{2}}
\end{array}\right.
$$

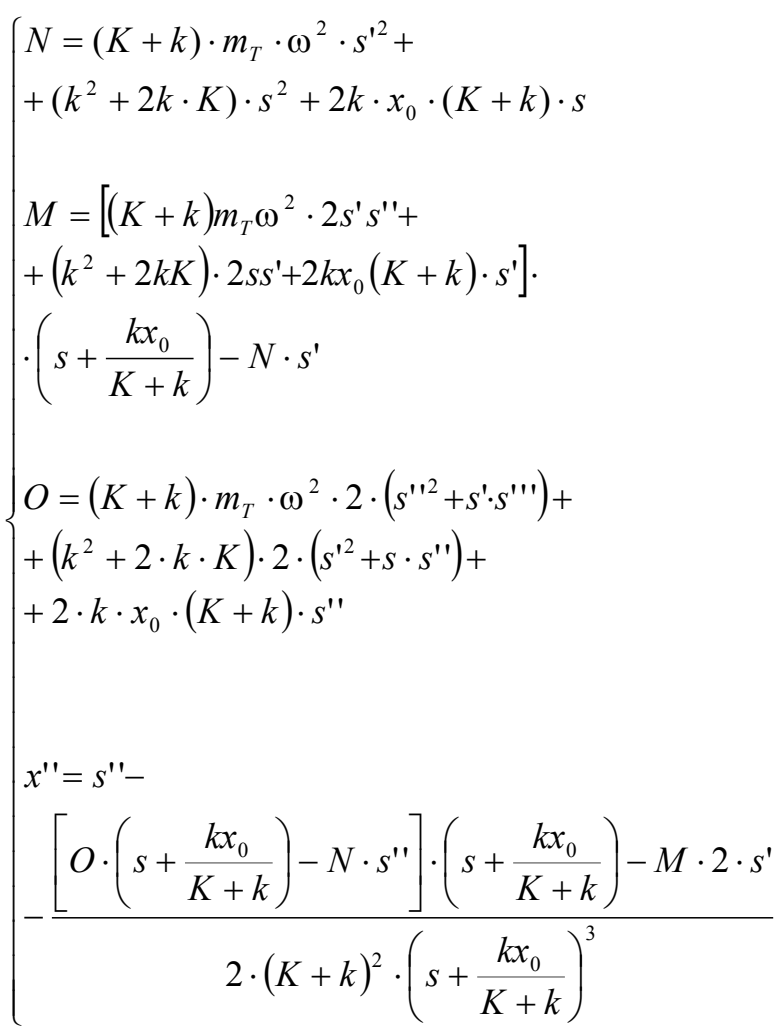

Further the acceleration of the tappet can be determined directly real (dynamic) using the relation (10).

$$
\ddot{x}=x^{\prime \prime} \cdot \omega^{2}+x^{\prime} \cdot \varepsilon
$$

\section{DYNAMIC SYNTHESIS}

Give the following parameters:

$\mathrm{r}_{0}=0.013 \quad[\mathrm{~m}] ; \mathrm{r}_{\mathrm{b}}=0.005 \quad[\mathrm{~m}] ; \mathrm{h}=0.008$ $[\mathrm{m}] ; \mathrm{e}=0.01[\mathrm{~m}] ; \mathrm{x}_{0}=0.03[\mathrm{~m}] ; \varphi_{\mathrm{u}}=\pi / 2 ; \varphi_{\mathrm{c}}=\pi / 2$; $\mathrm{K}=5000000[\mathrm{~N} / \mathrm{m}] ; \mathrm{k}=20000[\mathrm{~N} / \mathrm{m}] ; \mathrm{m}_{\mathrm{T}}=0.1$ $[\mathrm{kg}] ; \mathrm{M}_{\mathrm{C}}=0.2[\mathrm{~kg}] ; \mathrm{n}_{\text {motor }}=5500[\mathrm{rot} / \mathrm{min}]$.

To sum up dynamically based on a computer program, you can vary the input data until the corresponding acceleration is obtained (see Figure 2). It then summarizes the corresponding cam profile (Figure 3) using the relations (11).

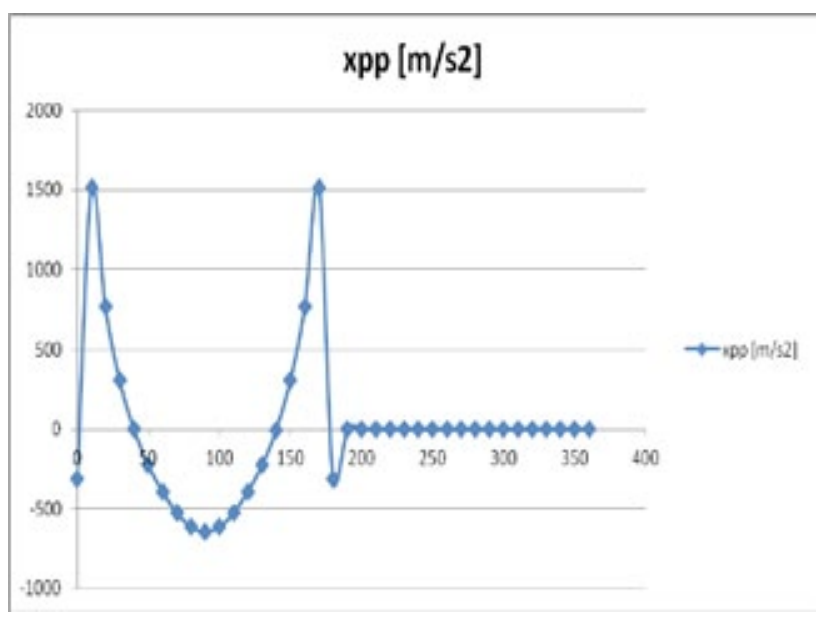

Fig. 2 Dynamic diagram to the rotary cam with translated follower with roll

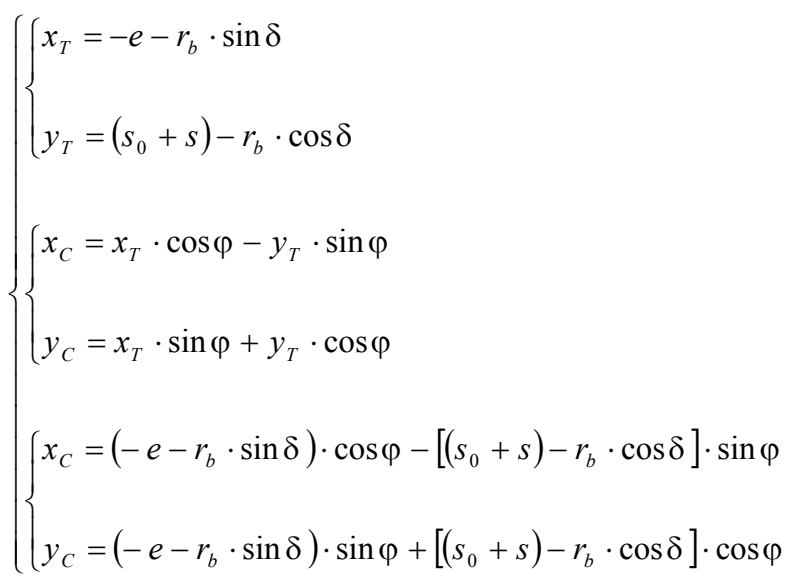




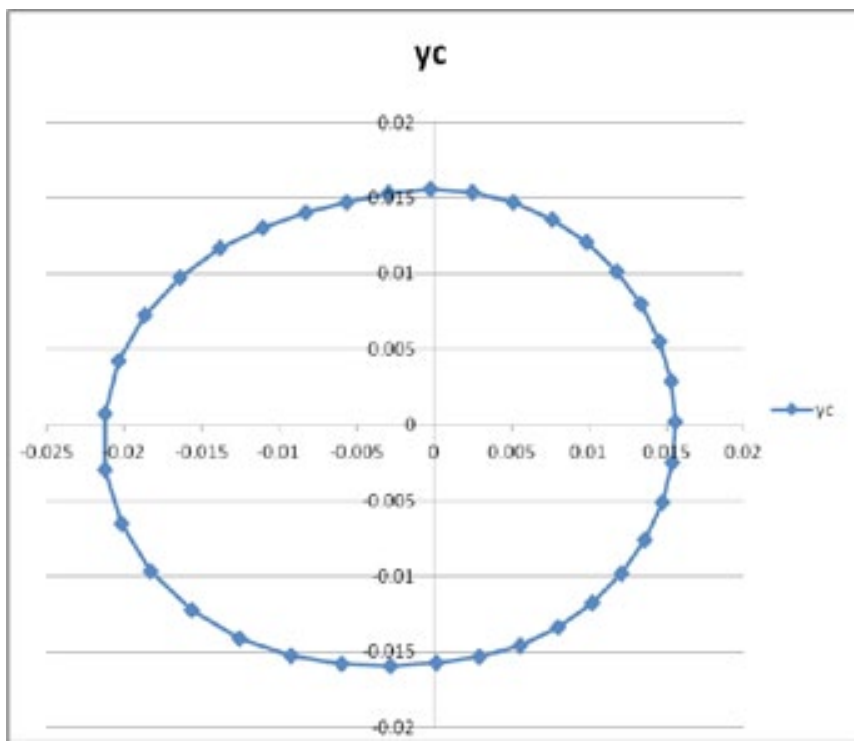

Fig. 3 The cam profile to the rotary cam with translated follower with roll

$r_{b}=0.003[\mathrm{~m}] ; e=0.003[\mathrm{~m}] ; h=0.006[\mathrm{~m}] ; r_{0}=0.013$ $[\mathrm{m}] ; \varphi_{0}=\pi / 2[\mathrm{rad}]$;

\section{THE GEOMETRY OF THE ROTARY CAM AND THE TRANSLATED FOLLOWER WITH ROLL}

Now, we shall see the geometry of a rotary cam with translated follower with roll (Figure 4). The cam rotation sense is positive (trigonometric).

We can make the geometrical synthesis of the cam profile with the help of the cinematics of the mechanism. One uses as well the reduced speed, s'

$$
\mathrm{OA}=\mathrm{r}=\mathrm{r} \mathrm{A} ; \mathrm{r}^{2}=\mathrm{r}_{\mathrm{A}}^{2}
$$

It establishes a system fixed Cartesian, $\mathrm{xOy}$ $=\mathrm{x}_{\mathrm{f}} \mathrm{Oy}_{\mathrm{f}}$, and a mobil Cartesian system, $\mathrm{xOy}=$ $\mathrm{x}_{\mathrm{m}} \mathrm{Oy}_{\mathrm{m}}$ fixed with the cam.

From the lower position 0 , the tappet, pushed by cam, uplifts to a general position, when the cam rotates with the $\varphi$ angle. The contact point $A$, go from $A_{i}{ }^{0}$ to $A^{0}$ (on the cam), and to $A$ (on the tappet). The position angle of the point $A$ from the tappet is $\theta_{f}$, and from the cam is $\theta_{\mathrm{m}}$. We can determine the coordinates of the point $\mathrm{A}$ from the tappet (12), and from the cam (13).

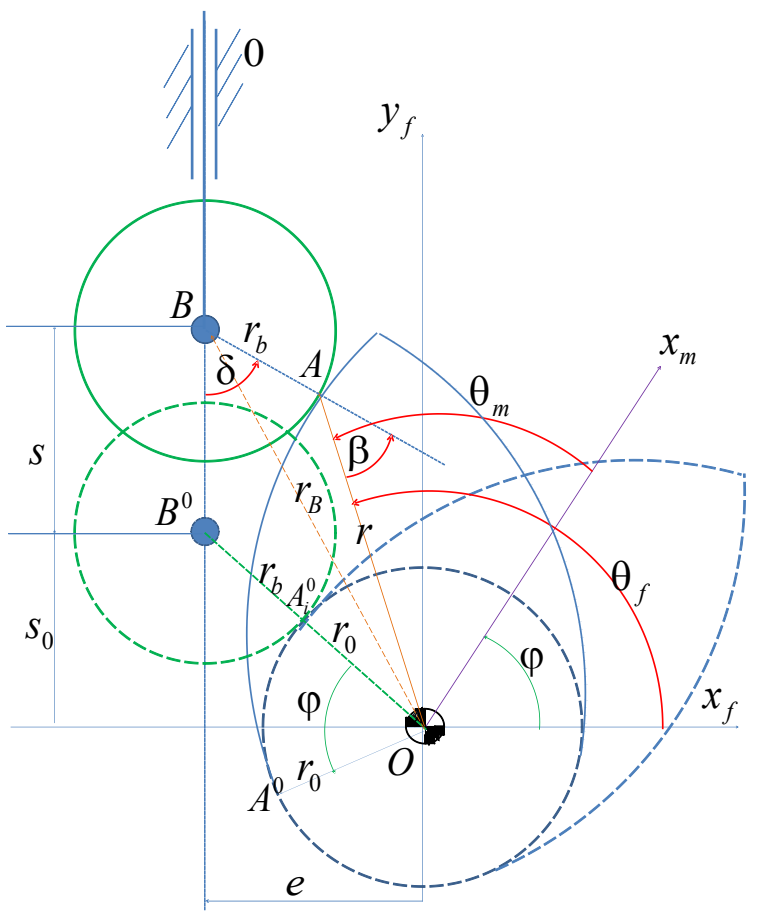

$\omega$

Fig. 4 The geometry of the rotary cam with translated follower with roll

$$
\left\{\begin{array}{l}
x_{T} \equiv x_{A}^{f}=-e+r_{b} \cdot \sin \delta= \\
=r_{A} \cdot \cos \theta_{f}=r \cdot \cos \theta_{f} \\
y_{T} \equiv y_{A}^{f}=s_{0}+s-r_{b} \cdot \cos \delta= \\
=r_{A} \cdot \sin \theta_{f}=r \cdot \sin \theta_{f}
\end{array}\right.
$$




$$
\left\{\begin{array}{l}
x_{c} \equiv x_{A}^{m}=r_{A} \cdot \cos \theta_{m}= \\
=r \cdot \cos \left(\theta_{f}-\varphi\right)= \\
=r \cos \theta_{f} \cos \varphi+r \sin \theta_{f} \sin \varphi= \\
=x_{T} \cos \varphi+y_{T} \sin \varphi= \\
=\left(-e+r_{b} \cdot \sin \delta\right) \cdot \cos \varphi+ \\
+\left(s_{0}+s-r_{b} \cdot \cos \delta\right) \cdot \sin \varphi \\
y_{c} \equiv y_{A}^{m}=r_{A} \cdot \sin \theta= \\
=r \cdot \sin \left(\theta_{f}-\varphi\right)= \\
=r \sin \theta_{f} \cos \varphi-r \sin \varphi \cos \theta_{f}= \\
=y_{T} \cos \varphi_{-} x_{T} \sin \varphi= \\
=\left(s_{0}+s-r_{b} \cdot \cos \delta\right) \cdot \cos \varphi- \\
-\left(-e+r_{b} \cdot \sin \delta\right) \cdot \sin \varphi
\end{array}\right.
$$

One uses and the next relationships (where the pressure angle $\delta$ was obtained with the classic Antonescu P. method):

$$
\left\{\begin{array}{l}
s_{0}=\sqrt{\left(r_{0}+r_{b}\right)^{2}-e^{2}} \\
\cos \delta=\frac{s_{0}+s}{\sqrt{\left(s_{0}+s\right)^{2}+\left(s^{\prime}-e\right)^{2}}} \\
\sin \delta=\frac{s^{\prime}-e}{\sqrt{\left(s_{0}+s\right)^{2}+\left(s^{\prime}-e\right)^{2}}} \\
\operatorname{tg} \delta=\frac{s^{\prime}-e}{s_{0}+s}
\end{array}\right.
$$

\section{DETERMINING THE FORCES, THE VELOCITIES AND THE EFFICIENCY}

The driving force $\mathrm{F}_{\mathrm{m}}$, perpendicular on $\mathrm{r}$ in

$\mathrm{A}$, is divided in two components: $\mathrm{F}_{\mathrm{n}}$, the normal force, and $\mathrm{F}_{\mathrm{a}}$, a force of slipping. Fn is di- vided, as well, in two components: $\mathrm{F}_{\mathrm{T}}$ is the transmitted (the utile) force, and $F_{R}$ is a radial force which bend the tappet (see 15, and the Figure 5).

$$
\left\{\begin{array}{l}
\left\{\begin{array}{l}
F_{n}=F_{m} \cdot \cos \alpha \\
v_{n}=v_{m} \cdot \cos \alpha
\end{array}\right. \\
\left\{\begin{array}{l}
F_{T}=F_{n} \cdot \cos \delta=F_{m} \cdot \cos \alpha \cdot \cos \delta \\
v_{T}=v_{n} \cdot \cos \delta=v_{m} \cdot \cos \alpha \cdot \cos \delta
\end{array}\right. \\
\mu_{i}=\frac{P_{u}}{P_{c}}=\frac{F_{T} \cdot v_{T}}{F_{m} \cdot v_{m}}= \\
=\frac{F_{m} \cdot \cos \alpha \cdot \cos \delta \cdot v_{m} \cdot \cos \alpha \cdot \cos \delta}{F_{m} \cdot v_{m}}= \\
=(\cos \alpha \cdot \cos \delta)^{2}=\cos { }^{2} \alpha \cdot \cos { }^{2} \delta
\end{array}\right.
$$

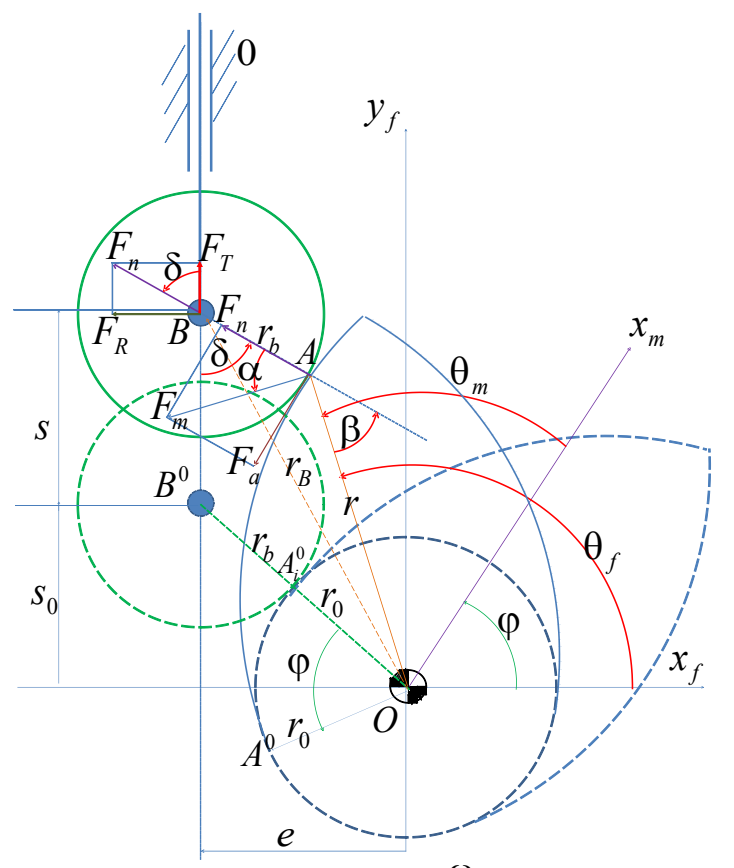

$\omega$

Fig. 5 Forces and velocities of the rotary cam with translated follower with roll 


\section{GEOMETRO-KINEMATICS SYNTHESIS}

For a good work one proposes to make a new geometro-kinematics synthesis of the cam profile, using some new relationships (16).

$$
\left\{\begin{array}{l}
x_{T} \equiv x_{A}^{f}=-e+r_{b} \cdot \sin \delta= \\
=r_{A} \cdot \cos \theta_{f}=r \cdot \cos \theta_{f} \\
y_{T} \equiv y_{A}^{f}=s_{0}+s-r_{b} \cdot \cos \delta=(16) \\
=r_{A} \cdot \sin \theta_{f}=r \cdot \sin \theta_{f}
\end{array}\right.
$$$$
\left\{\begin{array}{l}
x_{c} \equiv x_{A}^{m}=r_{A} \cdot \cos \theta_{m}= \\
=r \cdot \cos \left(\theta_{f}-\varphi\right)= \\
=r \cos \theta_{f} \cos \varphi+r \sin \theta_{f} \sin \varphi= \\
=x_{T} \cos \varphi+y_{T} \sin \varphi= \\
=\left(-e+r_{b} \cdot \sin \delta\right) \cdot \cos \varphi+ \\
+\left(s_{0}+s-r_{b} \cdot \cos \delta\right) \cdot \sin \varphi \\
y_{c} \equiv y_{A}^{m}=r_{A} \cdot \sin \theta_{m}= \\
=r \cdot \sin \left(\theta_{f}-\varphi\right)= \\
=r \sin \theta_{f} \cos \varphi-r \sin \varphi \cos \theta_{f}= \\
=y_{T} \cos \varphi-x_{T} \sin \varphi= \\
=\left(s_{0}+s-r_{b} \cdot \cos \delta\right) \cdot \cos \varphi- \\
-\left(-e+r_{b} \cdot \sin \delta\right) \cdot \sin \varphi
\end{array}\right.
$$

One uses and the next relationships (where the pressure angle $\delta$ was obtained with the new Petrescu F. method):

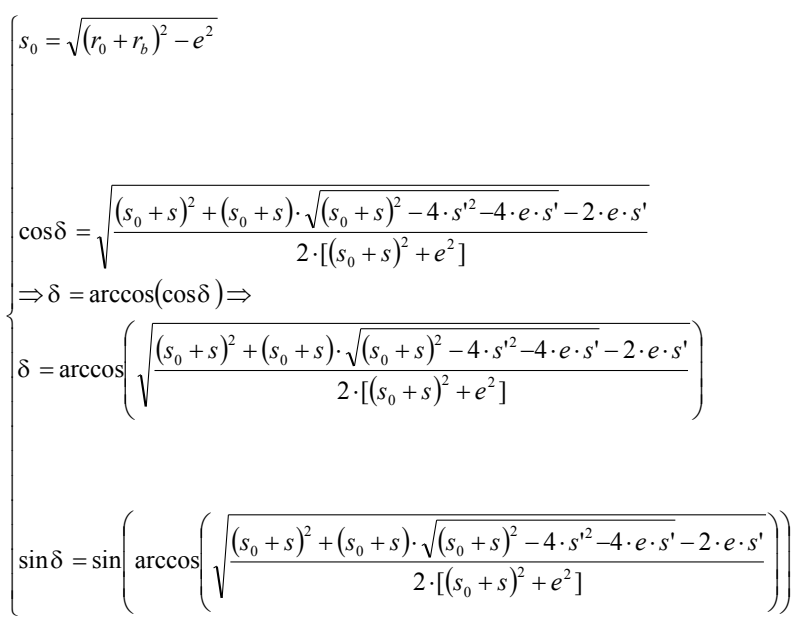

The new profile can be seen in the Figure 6 .

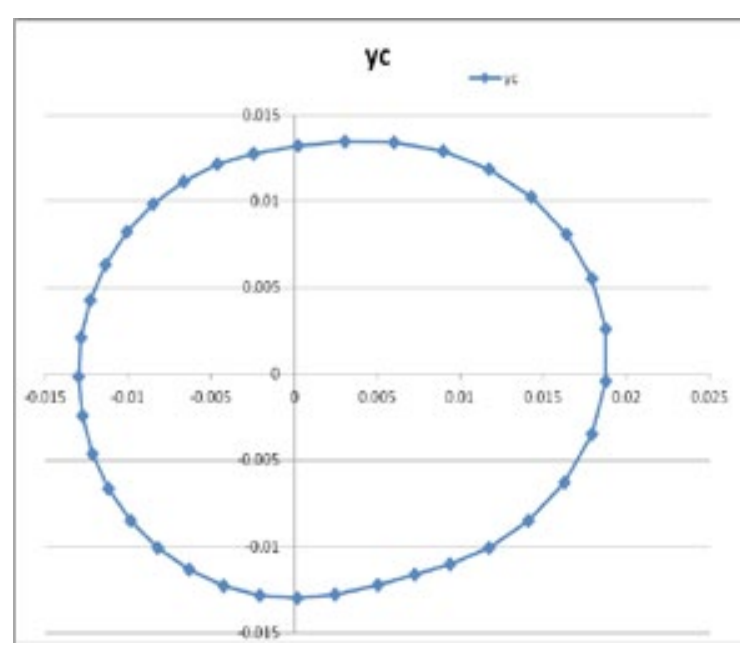

Fig. 6 The new cam profile to the rotary cam with translated follower with roll

$\mathrm{rb}=0.003[\mathrm{~m}] ; \mathrm{e}=0.003[\mathrm{~m}] ; \mathrm{h}=0.006[\mathrm{~m}] ; \mathrm{r} 0=0.013[\mathrm{~m}] ;$ $\varphi 0=\pi / 2[\mathrm{rad}] ;$ 


\section{DEMONSTRATION (EXPLICATION)}

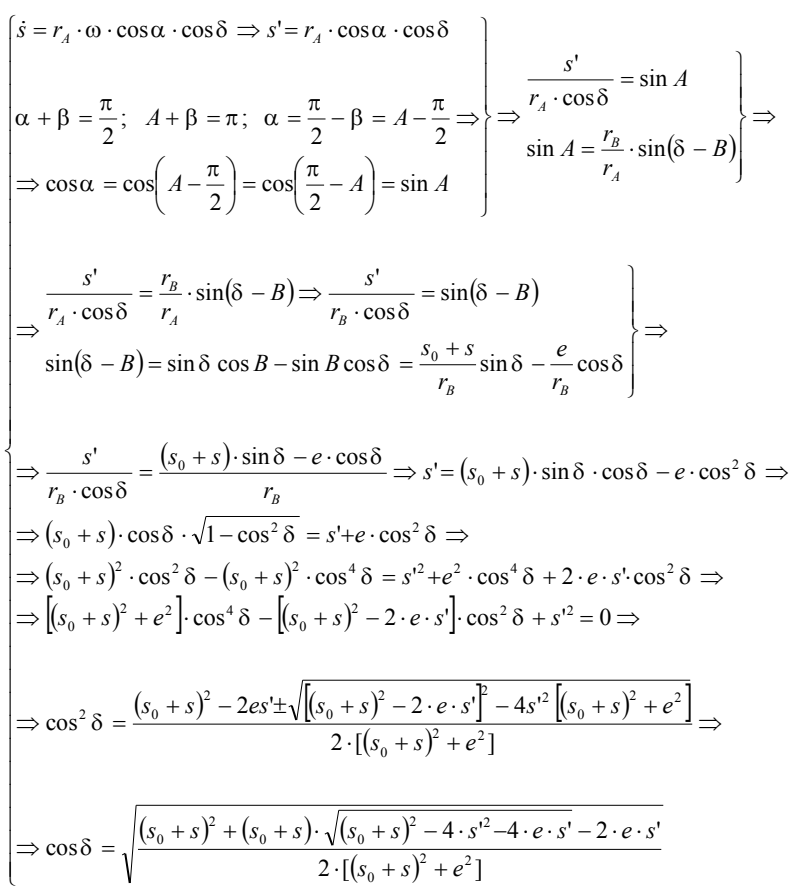

\section{CONCLUSIONS}

The presented method is the most elegant and direct method to determine the kinematics and dynamic parameters.

The dynamic synthesis can generate a cam profile which will work without vibrations.

\section{REFERENCES}

[1] Angelas J., Lopez-Cajun C., Optimal synthesis of cam mechanisms with oscillating flat-face followers. Mechanism and Machine Theory 23,(1988), Nr. 1., p. 1-6., 1988.

[2] Antonescu, P., Petrescu, F., Antonescu, O., Contributions to the Synthesis of The Rotary Disc-Cam Profile, In VIII-th International Conference on the Theory of Machines and Mechanisms, Liberec, Czech Republic, p. 51-56, 2000.

[3] Giordana F., s.a., On the influence of measurement errors in the Kinematic analysis of cam. Mechanism and Machine Theory 14 (1979), nr. 5., p. 327-340, 1979.
[4] Hain K., Optimization of a cam mechanism to give goode transmissibility maximal output angle of swing and minimal acceleration. Journal of Mechanisms 6 (1971), Nr. 4., p.419-434.

[5] Petrescu F., Petrescu R., Contributii la sinteza mecanismelor de distributie ale motoarelor cu ardere internã. In E.S.F.A.'95, Vol. 1., p. 257-264., Bucuresti, mai 1995.

[6] Petrescu, F.I., Petrescu, R.V. Contributions at the dynamics of cams. In the Ninth IFToMM International Symposium on Theory of Machines and Mechanisms, SYROM 2005, Bucharest, Romania, 2005, Vol. I, p. 123-128.

[7] Petrescu, F.I., Petrescu, R.V., Popescu N., The efficiency of cams. In the Second International Conference "Mechanics and Machine Elements", Technical University of Sofia, November 4-6, 2005, Sofia, Bulgaria, Vol. II, p. 237-243.

[8] Petrescu F.I., ş.a., Cams Dynamic Efficiency Determination. In New Trends in Mechanisms, Ed. Academica - Greifswald, 2008, I.S.B.N. 978-3940237-10-1, p. 49-56.

[9] Taraza, D., "Accuracy Limits of IMEP Determination from Crankshaft Speed Measurements," SAE Transactions, Journal of Engines 111, p. 689697, 2002. 